\title{
Language and Music: Sound, Structure, and Meaning
}

\author{
L. Robert Slevc \\ University of Maryland, College Park \\ slevc@umd.edu
}

This is a postprint version of the following article: Slevc, L.R. (2012). Language and music: Sound, structure, and meaning. Wiley Interdisciplinary Reviews: Cognitive Science, 3(4), 483-492.

Published in final form at: http://dx.doi.org//10.1002/wcs.1186 


\section{Abstract}

Language and music are the most impressive examples of humans' capacity to process complex sound and structure. Though interest in the relationship between these two abilities has a long history, only recently has cognitive and neuroscientific research started to illuminate both what is shared and what is distinct between linguistic and musical processing. This review considers evidence for a link between language and music at three levels of analysis: sound, structure, and meaning. These links not only inform our understanding of language and music, but also add to a more basic understanding of our processing of complex auditory stimuli, abstract structure, meaning, and emotion.

\section{Introduction}

Speech and music are the most impressive examples of our ability to make sense out of sound. Many have suggested that there might be a relationship between these abilities: to pick just two examples, Charles Darwin famously suggested that language may have evolved from an early musical communicative system, ${ }^{1}$ and the American conductor and composer Leonard Bernstein proposed links between several specific aspects of language and music in an influential series of talks at Harvard in the 1970s. ${ }^{2}$ Investigations of the relationship between language and music have been approached in many ways and from many disciplines; this review focuses on research within the broad framework of cognitive science that investigates if, and how, the cognitive and neural processing of language and music are related.

The existence and nature of a language-music relationship is intriguing for at least two reasons. For one, studies on the relationship between language and music are often framed as a test of modularity. That is, do language and music rely on independent, encapsulated systems or do they instead rely on domain general processes? The answer is not yet clear: claims of a deep relationship between language and music ${ }^{2,3}$ contrast with claims that differences between these domains outweigh what are relatively superficial similarities. ${ }^{4,5}$ Of course, language and music are complex systems that involve many different processes; some of these processes may be shared while others may be domain specific. Therefore, the ways in which language and music rely on shared and on distinct cognitive/perceptual processes is likely to lead to a richer understanding of both domains. A second reason to investigate language-music relationships is that research on transfer from music to language (and vice versa) provides an interesting opportunity to investigate neural (and behavioural) plasticity. In particular, musicians have undertaken intense multisensory training that can lead to relatively dramatic changes in brain structure and function, ${ }^{6}$ and this training provides a window on neuroplastic changes and their influence on language processing. This paper reviews recent research on the relationship between language and music broken down into three general domains: sound, structure, and meaning.

\section{SOUND}

Perhaps the most obvious point of connection between language and music is that both rely on the analysis of complex sound. Are aspects of musical and linguistic sounds processed in similar ways? One might think not - reports of aphasic patients who can sing but not speak ${ }^{7}$ and amusic (tonedeaf) people with no obvious language deficits ${ }^{8}$ imply at least some separation of linguistic and musical abilities. And while the early stages of speech and music processing are likely shared-as 
with any type of auditory stimuli, both are first processed in the bilateral auditory temporal cortices-at some point the processing of language and music diverge with speech processing relying more on the left hemisphere and musical processing relying more on the right. ${ }^{9}$ One explanation for this division is that speech perception relies on a dedicated left-lateralized system that is independent of other forms of auditory perception (at least, as soon as a sound is identified as speech); ${ }^{10}$ this sort of account predicts little, if any, relationship between the processing of speech and music. ${ }^{11}$

However, hemispheric asymmetries for speech and music might not reflect cortical specialization for language and music per se; instead they might reflect more general differences in the auditory processing demands imposed by linguistic and musical stimuli. In particular, the specific aspects of sound that are most important in language and music differ: speech sounds rely primarily on timbre and very rapid temporal changes (on the order of 20-40 milliseconds) whereas musical sounds rely mostly on precise (and relatively slower) changes in pitch, or spectral (frequency) information. ${ }^{12,13}$ By this account, the left hemisphere is relatively specialized for rapid temporal processing whereas the right hemisphere focuses on spectral discrimination. ${ }^{9,14}$ Although this reduction of hemispheric asymmetries to temporal/spectral specialization may be an oversimplification, ${ }^{15,16}$ and theories on the hemispheric lateralization of music are complicated by evidence that lateralization of musical processing shifts as a function of musical training, ${ }^{17,18}$ the insight remains that asymmetries in speech vs. music perception could reflect an underlying auditory basis. Furthermore, lateralization for language and music is relative: both recruit a wide bilateral network of neural tissue ${ }^{14,19}$ suggesting that hemispheric lateralization reflects a hemispheric bias rather than a discrete specialization for the processing of linguistic versus musical sounds.

Thus one might imagine shared processing of certain aspects of speech and music, in particular of pitch information in speech and of timbral information in music. One might also imagine shared "higher-level" processing that applies to both domains, such as the ability to learn and manipulate abstract sound categories (whether those be based on timbre, time, or pitch). ${ }^{3,20}$ These possibilities have been addressed in two general ways. One is to look for music to language transfer effectsasking if musical skill and/or musical deficits predict how successfully or easily linguistic sound stimuli can be learned or processed. Studies using this approach typically investigate some aspect of speech perception as a function of musical ability, training, or in patients with musical deficits (note that measures of musical skill are sometimes treated as a continuous measure, but studies more commonly compare a group of "musicians" with a group of "non-musicians"). A second approach is to look for language to music transfer effects; for example, by investigating pitch processing in speakers of tone vs. non-tone languages, or by asking if people with deficits in speech sound perception have trouble with musical perception.

\section{Sound: music to language transfer}

While it is true that speech does not rely primarily on pitch, the speech signal nonetheless includes important pitch-based information. This is perhaps most obvious in tone languages, where pitch is used contrastively (i.e., these languages include lexical items differing only in their relative pitch or pitch pattern). Tone languages make up approximately half of the world's languages and are common throughout sub-Saharan Africa and Asia (the most widely spoken language of this type is Mandarin Chinese). ${ }^{21}$ Even in languages that do not use pitch lexically, a wealth of linguistic and emotional information is conveyed by pitch modulations in speech; for example, consider the 
intonation difference that signals whether something is a question or a statement in English. This suggests that the ability to process lexical tone, prosodic changes, and the like might rely on the same mechanisms involved in musical perception.

Indeed, there is evidence that musicians are more sensitive to emotional prosodic cues than are non-musicians ${ }^{22,23}$ and are better able to detect small pitch changes in speech as well as in music. ${ }^{24}$ Musical training also predicts how well native English speakers learn the lexical tones of Mandarin Chinese. ${ }^{25-27}$ Interestingly, the advantage shown by musicians in linguistic pitch processing is reflected in the fidelity of pitch encoding in the auditory brainstem, ${ }^{28-30}$ suggesting that musical experience exerts effects on very early in the processing of speech, presumably via projections from cortical regions (i.e., corticofugal projections; see ref. 30 for a review).

Although one might expect music to language transfer effects to occur only for pitch-based linguistic contrasts, musical training (and/or ability on musical tasks) predicts skill on some non-pitch related linguistic abilities as well. For example, musicians can better discriminate differences in vowel quality and timing, ${ }^{31}$ voice onset time, ${ }^{32}$ and can more accurately perceive speech in degraded conditions (e.g., speech in noise) than can non-musicians. ${ }^{33,34}$ Findings like these may reflect a relatively general advantage in auditory selective attention associated with musical training. ${ }^{35}$ Musical ability also predicts language learning in children, correlating with phonological awareness and reading development, ${ }^{36-38}$ and in adults, predicting how well late learners acquire both receptive and productive second-language phonology (even after controlling for a variety of other relevant factors). ${ }^{20}$

It is important to recognize that most of these findings are correlational and thus do not necessarily support a causal relationship between music and language. This concern is lessened, however, given evidence that there are not pre-existing neural, cognitive, motoric, or musical differences between children who do and do not undergo later musical training. ${ }^{39}$ In addition, a longitudinal study that pseudorandomly assigned children to training in either music or painting found positive music to language transfer after only six months of training. Specifically, children who received musical training (but not children who received painting training) showed enhanced electrophysiological responses to pitch variations in music and in speech and also showed greater improvements on a behavioural reading task. ${ }^{40}$

These findings give considerable support for transfer of musical training to language abilities, but this conclusion is challenged by reports of musical processing deficits in people with no obvious speech perception difficulties. These are people with both congenital and acquired amusia (a form of auditory agnosia that is purportedly specific to music) who seem to have normal language function $^{41,42}$ (see ref. 4 for a review). However, recent findings suggest that congenital amusics actually do have problems with aspects of language that are based on pitch, in particular with speech intonation ${ }^{43}$ and, in severe cases, with lexical tone. ${ }^{44}$ Deficits in musical pitch perception are also associated with language deficits not based on pitch information per se, namely in phonological and phonemic awareness. ${ }^{45}$ Subtle (and, sometimes not so subtle) linguistic deficits tend to accompany acquired amusia (i.e., amusia resulting from brain damage) as well. ${ }^{46}$ 
Musically based treatments for language deficits

Evidence for music to language transfer raises the possibility that musical interventions might be useful in the treatment of language deficits. For example, many have noted that aphasic patients can sometimes sing better than they can speak, ${ }^{7,47}$ and indeed there is some evidence that musically based speech therapy can help with recovery of language production following stroke (perhaps by engaging right hemisphere homologues to damaged speech production networks in the left hemisphere). ${ }^{48}$ Music therapy may also help improve speech production in Parkinson's disease ${ }^{49}$ and in nonverbal children with autism. ${ }^{50}$ Music does not only help language production: listening to music after stroke is also associated with better recovery of receptive auditory abilities. ${ }^{51}$ The mechanisms of these effects are not yet well understood, and probably involve attentional, behavioural, cognitive and perceptual, as well as emotional and social factors. ${ }^{52}$ Nonetheless, the influence of music on language processing suggests that the efficacy of musical therapy for language deficits, as well as the mechanisms underlying these therapies, deserve more investigation.

There is thus mounting evidence for some degree of music to language transfer: musical training and ability are associated with better learning of linguistic sounds and with higher fidelity neural encoding of linguistic pitch information, and the supposedly music-specific deficits in amusia seem to be associated with subtle speech perception deficits. One recent hypothesis suggests that the reason musical ability transfers to language processing is because musical training "exercises" overlapping neural functions in a way that requires more (or at least a different sort of) precision, conveys greater emotional force, is highly repetitive and attention demanding. ${ }^{53}$ These demands presumably lead to many of the cognitive and neural changes associated with musical training, and are particularly relevant to the processing of speech.

\section{Sound: language to music transfer}

The idea that music to language transfer reflects overlap between these systems suggests that one should observe language to music transfer as well. Although the possible effects of language on musical processing have received less attention than the effects of music on language, there is some evidence that language experience can, in fact, influence musical sound perception. For example, speakers of tone languages show some non-linguistic pitch processing advantages compared to speakers of non-tone languages; in particular in the accurate perception and reproduction of musical pitch intervals and melodies (but not of individual pitches). ${ }^{54}$ Fluency in a tone language is also associated with a greater likelihood of possessing absolute pitch. ${ }^{55,56}$ However, tone-language experience does not seem to confer an advantage in relative pitch processing, ${ }^{57}$ which is generally more relevant to music perception than is absolute pitch. And, while one might predict that tone language speakers would be less susceptible to congenital amusia than speakers of non-tone languages, amusia appears to be equally prevalent across language types. ${ }^{44}$ Finally, the more veridical encoding of pitch in the brainstem associated with speaking a tone language is not necessarily accompanied by better performance on pitch discrimination tasks (in contrast to musical training, which is associated with both higher fidelity brainstem encoding and better pitch discrimination performance). ${ }^{58}$ One explanation for this discrepancy between positive and negative findings of language-to-music transfer is that there is an important difference between the perception of pitch per se (in identification and discrimination tasks where language to music transfer has been observed) and perception of pitch intervals (where such transfer does not seem to 
occur). Alternatively, these mixed findings might be an artefact of the specific language investigated (most work on language-to-music transfer investigates speakers of Mandarin Chinese) or might simply reflect the overall scarcity of research on transfer from language to music.

Language to music transfer is also called into question by cases of aphasia without amusia (i.e., patients with preserved musical ability despite severe language deficits). ${ }^{7,59-62}$ Perhaps the most famous of these cases is the Russian composer Vissarion Shebalin, who composed several wellreceived works, including his fifth symphony, after suffering a series of strokes that left him with profound language deficits. ${ }^{60}$ Tzortzis and colleagues have pointed out that all documented cases of aphasia without amusia involve professional musicians, ${ }^{62}$ suggesting that these dissociations may reflect cortical changes in musical processing as a function of extensive training. ${ }^{17,18}$ Alternatively, this might simply reflect musicians' greater opportunity to demonstrate preserved musical competence in the face of severe language difficulties. The critical cases (within the domain of sound processing) are individuals with deficits specific to speech perception without corresponding deficits in music perception, namely cases of verbal auditory agnosia or pure word deafness. There are a few case studies of individuals with pure word deafness who seem to have (relatively) unimpaired musical ability or even increased musical interest/ability ${ }^{61}$ (see also Oliver Sacks' book Musicophilia $^{63}$ for some interesting anecdotal cases). However these studies have not looked at musical perception in detail (i.e., increased interest in music does not necessarily imply preserved processing of all aspects of musical sounds), and most studies that have looked carefully at music perception abilities find moderate to severe musical impairment in at least some aspects of musical perception. ${ }^{16,61}$

There is thus mixed evidence for transfer from linguistic to musical sound processing overall, though there is relatively little data on this direction of transfer (compared to the larger body of research on transfer from music to language). This reflects practical constraints, at least partially: musical abilities and training vary widely in the population, and so it is relatively straightforward to investigate the influence of intense musical training on other abilities such as language. In contrast, essentially all humans are language experts, thus finding sufficient variability to investigate transfer is somewhat more challenging. Nonetheless, interest is growing in the influence of different types of language background (especially experience with tone compared to non-tone languages) on music processing, with intriguing results so far.

\section{STRUCTURE}

Parallels between language and music do not stop with the processing of complex sound; both are richly structured systems and a number of scholars have pointed out similarities between the structure of language and of music. ${ }^{3}$ The most well known comparisons of this type are those that rely on insights from formal linguistics to describe musical structure. This tradition goes back to at least the mid 1970s, when the noted composer, conductor, and writer Leonard Bernstein gave a series of lectures inspired by linguistic theory, drawing analogies between language and music. ${ }^{2}$ Indeed, formalisms akin to linguistic syntactic theory have been successfully used to describe "musical grammar", focusing primarily on tonal and metrical structure ${ }^{64-67}$ However, while linguistic and musical structure can be described using similar formalisms, this comparison can be misleading as there are considerable differences in the kinds of structural relationships that they capture. In fact, there may be more differences than similarities between linguistic and musical structure: music 
has no analogues to many aspects of linguistic syntax like part of speech (e.g., nouns and verbs) or grammatical agreement, and language does not use periodic rhythmic structure in a way comparable to music. ${ }^{3,5}$ Nevertheless, there is evidence that structural processing in language and music may indeed rely on shared processes for integrating time-spanning hierarchical relationships. ${ }^{3,68}$

\section{Linguistic structure and harmonic syntax}

Given that both language and music involve the conversion of complex auditory sequences into meaningful structures, it is reasonable to hypothesize a relationship. Some evidence for this comes from neural similarities in the processing of musical and linguistic syntax. In particular, violations of musical key structure lead to electrophysiological responses that are indistinguishable from those elicited by violations of linguistic syntactic structure, ${ }^{69}$ children with syntactic deficits in language processing (specific language impairment) have correspondingly impaired processing of musical syntax, ${ }^{70}$ and musical syntactic processing recruits inferior frontal brain regions that are characteristic of linguistic syntactic processing. ${ }^{71-73}$ However, cases where unimpaired processing of linguistic syntax coincides with insensitivity to harmonic structure ${ }^{74,75}$ and cases where significant language impairments (including agrammatism) are accompanied by preserved use of harmonic structure, ${ }^{59-62}$ give strong evidence for a dissociation between at least some aspects of syntax in language and music.

This discrepancy between the neurological overlap and neuropsychological dissociations between linguistic and musical syntax led to the proposal that language and music rely on separate syntactic representations, but also on shared processes to integrate these separable elements (the shared syntactic integration resource hypothesis). ${ }^{3,68} \mathrm{~A}$ key prediction of this hypothesis is that simultaneous processing of syntax in language and in music should lead to interactive effects. This prediction has now been confirmed in both behavioural and electrophysiological experiments where processing difficulty due to linguistic syntactic manipulations interacts with harmonic manipulations in a concurrently presented musical phrase. Such an interaction has been demonstrated for several different types of linguistic manipulations, including syntactic violations, ${ }^{76-78}$ syntactic ambiguity, ${ }^{79}$ and syntactic complexity, ${ }^{80}$ and emerges even when the harmonic "violation" is actually an acceptable, though structurally unexpected, chord. ${ }^{78}$ Importantly, the interactive effects shown in these experiments appear to be specific to syntax, as interactions do not arise with non-structural musical or linguistic manipulations (e.g., timbral unexpectancy in music or semantic unexpectancy in language).

Still, so far only two fMRI studies have directly compared neural activation to language and music in the same participants, and both have found little evidence for overlap. ${ }^{81,82}$ This lack of overlap has been taken to support largely independent neural networks for linguistic and musical syntactic processing, however this conclusion may be premature. For one, neither of these studies isolated structural processing in music and language; in particular, both used relatively coarse manipulations to isolate musically relevant activation (one comparing intact to scrambled musical phrases ${ }^{81}$ and one comparing intact music to silence ${ }^{82}$ ). Secondly, one study found no left frontal activation for either linguistic syntax or musical syntax. ${ }^{82}$ This second point, in particular, supports the view that the frontal regions typically involved in linguistic and musical syntactic processing may not reflect 
operations of syntax per se, but rather other cognitive processes like working memory and cognitive control that are critical for structural processing. ${ }^{83}$

If so, this raises a number of interesting questions about exactly what sorts of shared cognitive processes underlie linguistic and musical syntax. There are (at least) two likely candidates: One is the information manipulation and control processes broadly termed working memory and executive functioning that rely on prefrontal cortical regions. Some tantalizing evidence for a role of executive functions and working memory in musical processing comes from evidence that even short-term musical training leads to improvements in non-musical executive function and verbal intelligence tasks. ${ }^{84} \mathrm{~A}$ second type of process that might underlie structural processing in language and music is implicit learning (i.e., the ability to uncover and abstract structure from noisy input). ${ }^{85}$ There is increasing evidence that implicit learning underlies many aspects of linguistic and musical processing ${ }^{86,87}$ for example, musical training is associated with better learning of both musical and linguistic structures in an implicit learning paradigm. ${ }^{88}$ While there is still little work investigating shared roles of executive functions and implicit learning in linguistic and musical structure, the comparison of these two domains may prove critical to understand the specific roles general cognitive abilities play in both domains.

\section{Linguistic and musical rhythm}

Musical structure is not just harmonic; musical rhythm exhibits a similarly rich form of hierarchical organization. ${ }^{64}$ Although little work has investigated similarities between musical rhythmic structure and linguistic syntactic structure, some intriguing evidence for a relationship does come from evidence that synchronising to polyrhythms activates frontal regions often implicated in syntactic processing in language (those same inferior frontal areas mentioned above) ${ }^{89}$ In contrast, there are reports of individuals with selectively impaired musical rhythm perception without noticeable linguistic deficits, ${ }^{90}$ although there have not yet been careful comparisons of linguistic and musical rhythm processing in these cases.

There is, however, evidence for relationships between musical rhythm and rhythm in speech. For example, the musical rhythms of a particular language group are related to the rhythm of that language (e.g., Elgar's compositions reflect some rhythmic aspects of spoken English and Debussy's of spoken French) ${ }^{91,92}$ with clear enough differences that even musically untrained listeners can correctly classify instrumental music into different groups as a function of the composer's native language. ${ }^{93}$ These differences seem to reflect nonperiodic similarities in durational patterns of speech sounds and notes, and may reflect implicit knowledge of the rhythmic properties of one's native language which is then expressed in music. ${ }^{3}$ The rhythmic structure of language can also influence our perception of musical rhythm, for example English speakers tend to perceive repeating sequences of long and short sounds as "short-long" whereas Japanese speakers tend to perceive the same sequence as "long-short," likely reflecting the timing patterns of short phrases in those two languages. ${ }^{94}$

These findings suggest that one might observe some transfer from musical training to the processing of linguistic rhythm. Although little work has investigated this hypothesis to date, there is evidence that musical training confers an advantage in the ability to process lexical stress in an unfamiliar language, showing transfer at a prosodic level. ${ }^{95}$ Musical rhythm perception has also been linked with non-structural aspects of language processing, in particular with reading ability (as mediated by 
phonological development) both in normally developing children and in children with developmental dyslexia. ${ }^{96}$

The potential relationship between structural processing in language and music (be it harmonic or rhythmic or otherwise) is especially intriguing as structural processes have been argued to reflect a human-specific ability underlying language processing. ${ }^{97}$ Given the somewhat contradictory results thus far, an emerging possibility is that structural processes in language and music rely on common underlying cognitive mechanisms that are specialized for neither language nor music. If so, comparative work on language and music could provide an especially useful method to investigate these underlying mechanisms.

\section{MEANING}

It may seem surprising to posit a relationship between linguistic and musical meaning. One might even argue that the greatest differences between language and music are in this domain: the communication of specific denotative meanings is a core aspect of language, but it is far from obvious that there is a comparable sort of musical semantics. ${ }^{98}$ However, while music does not convey denotative or propositional meaning in a way comparable to language, music does appear to express and/or communicate other types of meaning, especially that with aesthetic, cultural, and emotional content, ${ }^{99}$ and there may be interesting parallels between these aspects of linguistic and musical semantics .

This suggests that it is necessary to consider different aspects of meaning to determine where one might find commonalities between language and music. Koelsch ${ }^{100}$ divides musical meaning into three categories: intra-musical meaning is meaning that emerges from the intra-relationships of musical information, extra-musical meaning (or designative meaning) is meaning that emerges via reference to the world outside of the music itself, and musicogenic meaning refers to interpretation of the emotional (or other) effects elicited by music (note that Meyer, ${ }^{101}$ among others, has proposed similar divisions). Intra-musical meaning is, by definition, specific to music, but relationships with language can be found within extra-musical and musicogenic forms of meaning.

Perhaps most analogous to linguistic semantics is extra-musical meaning, where music refers in some way to something in the world. Examples of this include tone painting, where music is written in a way that imitates something in the world (e.g., descending scales accompanying lyrics about falling), and leitmotifs, which are recurring musical themes that refer to specific person or situation. Music can also lead to extra-musical semantic expectancies. For example, people show an electrophysiological pattern characteristic of semantic incongruity in language (the N400) when reading a word incongruous with a preceding musical phrase ${ }^{102}$ (see ref. 100 for a review of related findings).

This sort of extra-musical reference is not, however, what people are typically referring to when talking about the meaning of a musical piece. Instead, one more typically refers to the emotional meaning of music (i.e., musicogenic meaning). It is clear that music can be used to express, and perhaps even communicate, a great deal of emotion, ${ }^{103}$ and the ability to perceive this musical meaning can be selectively lost with brain damage. ${ }^{104}$ And even though linguistic meaning is typically thought of as propositional and designative, language also expresses emotional meaning in ways more comparable to musicogenic meaning via prosodic and pragmatic cues. ${ }^{3}$ In fact, the acoustic 
features associated with emotional expression in music and in speech (features like pitch, intensity, contour, and rhythm) are remarkably similar and listeners can reliably identify intended emotions based on these features in both spoken and musical stimuli. ${ }^{103}$ One specific example is that people perceive minor thirds in speech as expressing sadness, just as minor thirds convey sadness in music. ${ }^{105}$ These parallels support the hypothesis that listeners may even understand instrumental music by treating it as a form of "heightened speech." ${ }^{103,106}$

\section{Conclusion}

Cognitive scientists are increasingly interested in the relationship between language and music. This review highlighted research on similarities at the level of sound, structure, and meaning. Indeed, there is growing evidence that there are many similarities, both in terms of shared processing and in terms of transfer between these two complex abilities. These relationships have implications not only for our understanding of language and music-important goals in their own right-but also have considerable practical implications for the role of music in education and therapy. Still, it is important to realize that the study of language-music relations is in its infancy and there are a number of areas where research is notably lacking. One limitation deserves particular mention: nearly all the empirical research comparing language and music focuses on Western tonal music. Investigations of non-Western musical systems will likely provide important insights and challenges to the work discussed above. One interesting new line of research along these lines is work on bimusicality, ${ }^{107}$ which likely will relate interestingly to the large body of research on bilingualism. ${ }^{108}$

Research on the relationship of language and music is moving beyond the question of modularity to investigate the underlying processes that shape both shared and distinct aspects of these two complex domains. Our growing understanding of the brain's relative specializations for processing different kinds of auditory stimuli, of the cognitive mechanisms underlying structural processing across domains, and of the communicative and expressive nature of both language and music is moving us closer toward a better understanding of our amazing ability to make sense out of sound.

Notes

The author would like to thank Eliana Sudikoff for research assistance and Aniruddh Patel and Elizabeth Redcay for helpful comments on an earlier version of this manuscript.

\section{References}

1. Darwin C. The Descent of Man, and Selection in Relation to Sex. London: John Murray; 1871.

2. Bernstein L. The Unanswered Question: Six Talks at Harvard. Cambridge, MA: Harvard University Press; 1976.

3. Patel AD. Music, Language, and the Brain. Oxford University Press; 2008.

4. Peretz I. The nature of music from a biological perspective. Cognition. 2006;100(1):1-32.

5. Jackendoff R. Parallels and nonparallels between language and music. Music Perception . 2009;26(3):195204.

6. Hyde KL, Lerch J, Norton A, Forgeard M, Winner EE, Alan C, Schlaug G. Musical training shapes structural brain development. The Journal of Neuroscience. 2009;29(10):3019-25. 
7. Yamadori A, Osumi Y, Masuhara S, Okubo M. Preservation of singing in Broca's aphasia. Journal of Neurology, Neurosurgery \& Psychiatry. 1977;40(3):221.

8. Peretz I, Hyde KL. What is specific to music processing? Insights from congenital amusia. Trends in Cognitive Sciences. 2003;7(8):362-367.

9. Zatorre RJ, Belin P, Penhune VB. Structure and function of auditory cortex: music and speech. Trends in Cognitive Sciences. 2002;6(1):37-46.

10. Liberman A, Whalen D. On the relation of speech to language. Trends in Cognitive Sciences. 2000;4(5):187196.

11. Peretz I, Coltheart M. Modularity of music processing. Nature Neuroscience. 2003;6(7):688-91.

12. Cheveigné A de. Pitch perception models. In: Plack C, Oxenham A, Fay RR, Popper AN, eds. Pitch. New York, NY: Springer; 2005:169-233.

13. Shannon R, Zeng F, Kamath V, Wygonski J. Speech recognition with primarily temporal cues. Science. 1995.

14. Hickok G, Poeppel D. The cortical organization of speech processing. Nature Reviews Neuroscience. 2007;8(5):393-402.

15. Scott SK, Wise RJS. The functional neuroanatomy of prelexical processing in speech perception. Cognition. 2004;92(1-2):13-45.

16. Slevc LR, Martin RC, Hamilton AC, Joanisse MF. Speech perception, rapid temporal processing, and the left hemisphere: A case study of unilateral pure word deafness. Neuropsychologia. 2011;49(2):216-30.

17. Bever TG, Chiarello RJ. Cerebral Dominance in Musicians and Nonmusicians. Science. 1974;185(4150):537-539.

18. Ohnishi T, Matsuda H, Asada T, et al. Functional Anatomy of Musical Perception in Musicians. Cerebral Cortex. 2001;11(8):754-760.

19. Alluri V, Toiviainen P, Jääskeläinen IP, et al. Large-scale brain networks emerge from dynamic processing of musical timbre, key and rhythm. NeuroImage. 2011.

20. Slevc LR, Miyake A. Individual Differences in Second-Language Proficiency: Does Musical Ability Matter? Psychological Science. 2006;17(8):675-681.

21. Maddieson I. Tone. In: Dryer MS, Haspelmath M, eds. The World Atlas of Language Structures Online. Munich: Max Planck Digital Library; 2011.

22. Thompson WF, Schellenberg EG, Husain G. Decoding speech prosody: do music lessons help? Emotion. 2004;4(1):46-64.

23. Lima CF, Castro SL. Speaking to the trained ear: Musical expertise enhances the recognition of emotions in speech prosody. Emotion. 2011;11(5):1021-1031.

24. Marques C, Moreno S, Castro SL, Besson M. Musicians detect pitch violation in a foreign language better than nonmusicians: behavioral and electrophysiological evidence. Journal of Cognitive Neuroscience. 2007;19(9):1453-63.

25. Delogu F, Lampis G, Belardinelli MO. From melody to lexical tone: Musical ability enhances specific aspects of foreign language perception. European Journal of Cognitive Psychology. 2010;22(1):46-61.

26. Marie C, Delogu F, Lampis G, Belardinelli MO, Besson M. Influence of musical expertise on segmental and tonal processing in Mandarin Chinese. Journal of Cognitive Neuroscience. 2011;23(10):2701-15.

27. Lee C-Y, Hung T-H. Identification of Mandarin tones by English-speaking musicians and nonmusicians. The Journal of the Acoustical Society of America. 2008;124(5):3235-48.

28. Wong PCM, Skoe E, Russo NM, Dees T, Kraus N. Musical experience shapes human brainstem encoding of linguistic pitch patterns. Nature Neuroscience. 2007;10(4):420-2.

29. Musacchia G, Sams M, Skoe E, Kraus N. Musicians have enhanced subcortical auditory and audiovisual processing of speech and music. Proceedings of the National Academy of Sciences. 2007;104(40):15894-8.

30. Kraus N, Chandrasekaran B. Music training for the development of auditory skills. Nature Reviews Neuroscience. 2010;11(8):599-605. 
31. Sadakata M, Sekiyama K. Enhanced perception of various linguistic features by musicians: A crosslinguistic study. Acta Psychologica. 2011.

32. Chobert J, Marie C, François C, Schön D, Besson M. Enhanced passive and active processing of syllables in musician children. Journal of Cognitive Neuroscience. 2011;23(12):3874-87.

33. Bidelman GM, Krishnan A. Effects of reverberation on brainstem representation of speech in musicians and non-musicians. Brain Research. 2010;1355:112-25.

34. Parbery-Clark A, Skoe E, Lam C, Kraus N. Musician enhancement for speech-in-noise. Ear and Hearing. 2009;30(6):653-61.

35. Strait DL, Kraus N, Parbery-Clark A, Ashley R. Musical experience shapes top-down auditory mechanisms: evidence from masking and auditory attention performance. Hearing Research. 2010;261(1-2):22-9.

36. Anvari SH, Trainor LJ, Woodside J, Levy BA. Relations among musical skills, phonological processing, and early reading ability in preschool children. Journal of Experimental Child Psychology. 2002;83(2):111-30.

37. Lamb SJ, Gregory AH. The relationship between music and reading in beginning readers. Educational Psychology. 1993;13(1):19-27.

38. Forgeard M, Schlaug G, Norton A, Rosam C, Iyengar U, Winner E. The relation between music and phonological processing in normal-reading children and children with dyslexia. Music Perception. 2008:383390.

39. Norton A, Winner E, Cronin K, Overy, K, Lee DJ, Schlaug G. Are there pre-existing neural, cognitive, or motoric markers for musical ability? Brain and Cognition. 2005;59(2):124-134.

40. Moreno S, Marques C, Santos A, Santos M, Castro SL, Besson M. Musical training influences linguistic abilities in 8-year-old children: more evidence for brain plasticity. Cerebral Cortex. 2009;19(3):712-723.

41. Geschwind N. The brain of a learning-disabled individual. Annals of Dyslexia. 1984;34:319-327.

42. Piccirilli M, Sciarma T, Luzzi S. Modularity of music: evidence from a case of pure amusia. Journal of Neurology, Neurosurgery, and Psychiatry. 2000;69(4):541-5.

43. Liu F, Patel AD, Fourcin A, Stewart L. Intonation processing in congenital amusia: discrimination, identification and imitation. Brain. 2010;133(Pt 6):1682-93.

44. Nan Y, Sun Y, Peretz I. Congenital amusia in speakers of a tone language: association with lexical tone agnosia. Brain. 2010;133(9):2635-42.

45. Jones JL, Lucker J, Zalewski C, Brewer C, Drayna D. Phonological processing in adults with deficits in musical pitch recognition. Journal of Communication Disorders. 2009;42(3):226-34.

46. Särkämö T, Tervaniemi M, Soinila S, et al. Cognitive deficits associated with acquired amusia after stroke: a neuropsychological follow-up study. Neuropsychologia. 2009;47(12):2642-51.

47. Straube T, Schulz A, Geipel K, Mentzel H-J, Miltner WHR. Dissociation between singing and speaking in expressive aphasia: the role of song familiarity. Neuropsychologia. 2008;46(5):1505-12.

48. Schlaug G, Norton A, Marchina S, Zipse L, Wan CY. From singing to speaking: facilitating recovery from nonfluent aphasia. Future Neurology. 2010;5(5):657-665.

49. Pacchetti C, Mancini F, Aglieri R, Fundaro C, Martignoni E, Nappi G. Active Music Therapy in Parkinson's Disease: An Integrative Method for Motor and Emotional Rehabilitation. Psychosomatic Medicine.

2000;393:386 -393.

50. Wan CY, Bazen L, Baars R, Libenson A, Zipse L, Zuk J, Norton A, Schlaug G. Auditory-motor mapping training as an intervention to facilitate speech output in non-verbal children with Autism: A proof of concept study. PLOS ONE. 2011;6(9):e25505.

51. Särkämö T, Pihko E, Laitinen S, et al. Music and speech listening enhance the recovery of early sensory processing after stroke. Journal of Cognitive Neuroscience. 2010;22(12):2716-27.

52. Koelsch S. A neuroscientific perspective on music therapy. Annals of the New York Academy of Sciences. 2009;1169:374-84.

53. Patel AD. Why would musical training benefit the neural encoding of speech? The OPERA hypothesis. Frontiers in Psychology. 2011;2(June):142. 
54. Pfordresher PQ, Brown S. Enhanced production and perception of musical pitch in tone language speakers. Attention, Perception, \& Psychophysics. 2009;71(6):1385-1398.

55. Deutsch D, Henthorn T, Marvin E, Xu H. Absolute pitch among American and Chinese conservatory students: Prevalence differences, and evidence for a speech-related critical period. The Journal of the Acoustical Society of America. 2006;119(2):719.

56. Deutsch D, Dooley K, Henthorn T, Head B. Absolute pitch among students in an American music conservatory: association with tone language fluency. The Journal of the Acoustical Society of America. 2009; 125(4):2398-403.

57. Hove MJ, Sutherland ME, Krumhansl CL. Ethnicity effects in relative pitch. Psychonomic Bulletin \& Review. 2010;17(3):310-6.

58. Bidelman GM, Gandour JT, Krishnan A. Musicians and tone-language speakers share enhanced brainstem encoding but not perceptual benefits for musical pitch. Brain \& Cognition. 2011;77(1):1-10.

59. Basso A, Capitani E. Spared musical abilities in a conductor with global aphasia and ideomotor apraxia. Journal of the Neurological Sciences. 1985;(48):407-412.

60. Luria AR, Tsvetkova LS, Futer DS. Aphasia in a composer. Journal of the Neurological Sciences. 1965;2(3):288-292.

61. Mendez MF. Generalized auditory agnosia with spared music recognition in a left-hander. Analysis of a case with a right temporal stroke. Cortex. 2001;37(1):139-50.

62. Tzortzis C, Goldblum MC, Dang M, Forette F, Boller F. Absence of amusia and preserved naming of musical instruments in an aphasic composer. Cortex. 2000;36(2):227-42.

63. Sacks O. Musicophilia. New York: Alfred A. Knopf; 2007.

64. Lerdahl F, Jackendoff R. A Generative Theory of Tonal Music. Cambridge, MA: MIT Press; 1983.

65. Lerdahl F. Tonal Pitch Space. New York, NY: Oxford University Press; 2001.

66. Longuet-Higgins HC. Perception of melodies. Nature. 1976;263:646-653.

67. Rohrmeier M. Towards a generative syntax of tonal harmony. Journal of Mathematics and Music. 2011;5(1):35-53.

68. Patel AD. Language, music, syntax and the brain. Nature Neuroscience. 2003;6(7):674-81.

69. Patel AD, Gibson E, Ratner J, Besson M, Holcomb PJ. Processing syntactic relations in language and music: an event-related potential study. Journal of Cognitive Neuroscience. 1998;10(6):717-33.

70. Jentschke S, Koelsch S, Sallat S, Friederici AD. Children with specific language impairment also show impairment of music-syntactic processing. Journal of Cognitive Neuroscience. 2008;20(11):1940-51.

71. Levitin DJ, Menon V. Musical structure is processed in "language" areas of the brain: a possible role for Brodmann Area 47 in temporal coherence. NeuroImage. 2003;20(4):2142-2152.

72. Maess B, Koelsch S, Gunter TC, Friederici AD, others. Musical syntax is processed in Broca's area: an MEG study. Nature Neuroscience. 2001;4(5):540-545.

73. Tillmann B, Koelsch S, Escoffier N, et al. Cognitive priming in sung and instrumental music: activation of inferior frontal cortex. NeuroImage. 2006;31(4):1771-82.

74. Peretz I, Kolinsky R, Tramo M, et al. Functional dissociations following bilateral lesions of auditory cortex. Brain. 1994;117:1283-301.

75. Ayotte J, Peretz I, Hyde K. Congenital amusia: a group study of adults afflicted with a music-specific disorder. Brain. 2002;125(Pt 2):238-51.

76. Koelsch S, Gunter TC, Wittfoth M, Sammler D. Interaction between syntax processing in language and in music: an ERP Study. Journal of Cognitive Neuroscience. 2005;17(10):1565-77.

77. Steinbeis N, Koelsch S. Shared neural resources between music and language indicate semantic processing of musical tension-resolution patterns. Cerebral Cortex. 2008;18(5):1169-78.

78. Hoch L, Poulin-Charronnat B, Tillmann B. The influence of task-irrelevant music on language processing: Syntactic and semantic structures. Frontiers in Psychology. 2011;2:1-10. 
79. Slevc LR, Rosenberg JC, Patel AD. Making psycholinguistics musical: Self-paced reading time evidence for shared processing of linguistic and musical syntax. Psychonomic Bulletin \& Review. 2009;16(2):374-381.

80. Fedorenko E, Patel AD, Casasanto D, Winawer J, Gibson E. Structural integration in language and music: evidence for a shared system. Memory \& Cognition. 2009;37(1):1-9.

81. Fedorenko E, Behr MK, Kanwisher N. Functional specificity for high-level linguistic processing in the human brain. Proceedings of the National Academy of Sciences. 2011;(i).

82. Rogalsky C, Rong F, Saberi K, Hickok G. Functional anatomy of language and music perception: temporal and structural factors investigated using functional magnetic resonance imaging. The Journal of Neuroscience . 2011;31(10):3843-52.

83. Novick JM, Trueswell JC, Thompson-Schill SL. Cognitive control and parsing: Reexamining the role of Broca's area in sentence comprehension. Cognitive, Affective, \& Behavioral Neuroscience. 2005;5(3):263-281.

84. Moreno S, Bialystok E, Barac R, et al. Short-Term Music Training Enhances Verbal Intelligence and Executive Function. Psychological Science. in press.

85. Ettlinger M, Margulis EH, Wong PCM. Implicit memory in music and language. Frontiers in Psychology. 2011;2:1-10.

86. Loui P, Wu EH, Wessel DL, Knight RT. A generalized mechanism for perception of pitch patterns. The Journal of Neuroscience. 2009;29(2):454-9.

87. Saffran JR. Statistical language learning: mechanisms and constraints. Current Directions in Psychological Science. 2003;12(4):110-114.

88. Francois C, Schön D. Musical expertise boosts implicit learning of both musical and linguistic structures. Cerebral Cortex. in press.

89. Vuust P, Wallentin M, Mouridsen K, Ostergaard L, Roepstorff A. Tapping polyrhythms in music activates language areas. Neuroscience Letters. 2011;494(3):211-6.

90. Phillips-Silver J, Toiviainen P, Gosselin N, et al. Born to dance but beat deaf: a new form of congenital amusia. Neuropsychologia. 2011;49(5):961-9.

91. Patel AD, Iversen JR, Rosenberg JC. Comparing the rhythm and melody of speech and music: The case of British English and French. The Journal of the Acoustical Society of America. 2006;119(5):3034.

92. Patel AD, Daniele JR. An empirical comparison of rhythm in language and music. Cognition. 2003;87(1):B35-B45.

93. Hannon EE. Perceiving speech rhythm in music: listeners classify instrumental songs according to language of origin. Cognition. 2009;111(3):404-10.

94. Iversen JR, Patel AD, Ohgushi K. Perception of rhythmic grouping depends on auditory experience. The Journal of the Acoustical Society of America. 2008;124(4):2263-71.

95. Kolinsky R, Cuvelier H, Goetry V, Peretz I. Music training facilitates lexical stress processing. Music Perception. 2009:235-246.

96. Huss M, Verney JP, Fosker T, Mead N, Goswami U. Music, rhythm, rise time perception and developmental dyslexia: perception of musical meter predicts reading and phonology. Cortex. 2011;47(6):674-89.

97. Hauser MD, Chomsky N, Fitch WT. The faculty of language: what is it, who has it, and how did it evolve? Science. 2002;298(5598):1569-79.

98. Kivy P. Music Alone: Philosophical Reflections on the Purely Musical Experience. Cornell University Press; 1990.

99. Cross I. Tolbert E. Music and meaning. In S. Hallam, I. Cross and M. Thaut (Eds.) The Oxford Handbook of Music Psychology. Oxford University Press. 2009:24-34.

100. Koelsch S. Towards a neural basis of processing musical semantics. Physics of Life Reviews. 2011;8(2):89105.

101. Meyer LB. Emotion and Meaning in Music. University of Chicago Press; 1961.

102. Koelsch S, Kasper E, Sammler D, et al. Music, language and meaning: brain signatures of semantic processing. Nature Neuroscience. 2004;7(3):302-7. 
103. Juslin, PN, Laukka, P. Communication of emotions in vocal expression and music performance: Different channels, same code? Psychological Bulletin. 2003;129(5):770-814.

104. Gosselin N, Peretz I, Johnsen E, Adolphs R. Amygdala damage impairs emotion recognition from music. Neuropsychologia. 2007;45(2):236-44.

105. Curtis ME, Bharucha JJ. The minor third communicates sadness in speech, mirroring its use in music. Emotion. 2010;10(3):335-48.

106. Spencer, H. The origin and function of music. Fraser's Magazine. 1857;56:396-408.

107. Wong PCM, Chan AHD, Roy A, Margulis EH. The bimusical brain is not two monomusical brains in one: evidence from musical affective processing. Journal of Cognitive Neuroscience. 2011;23(12):4082-93.

108. Bialystok E, Craik FIM, Green DW, Gollan TH. Bilingual minds. Psychological Science in the Public Interest. 2009;10(3):89-129.

\section{Further Reading/Resources}

Patel, A. D. (2008). Music, Language, and the Brain. Oxford University Press. 